\title{
Determination of colistin-related nephrotoxicity and risk factors in intensive care unit
}

\author{
Ayse Inci, ${ }^{1}$ Melike Korkmaz Toker, ${ }^{2}$ Ilhan Guney Bicer, ${ }^{2}$ Abdurrrahim Derbent, ${ }^{2}$ Ziya Salihoglu ${ }^{2}$ \\ ${ }^{1}$ Department of Infectious Diseases and Clinical Microbiology, University of Health Sciences, Istanbul Kanuni Sultan Suleyman Training and \\ Research Hospital, Istanbul, Turkey \\ ${ }^{2}$ Department of Anesthesiology and Reanimation, University of Health Sciences, Istanbul Kanuni Sultan Suleyman Training and Research \\ Hospital, Istanbul, Turkey
}

\begin{abstract}
OBJECTIVE: Colistin is a cationic polypeptide antibiotic with a cyclic structure that belongs to the polymyxin group. It was banned from clinical use because of its significant renal side effects, such as nephrotoxicity. However, the administration of colistin has recently been initiated again in the treatment of multi-drug resistant pathogens, such as Acinetobacter baumannii and Pseudomonas aeruginosa. Nephrotoxicity and neurotoxicity are the main problems encountered in the clinical use of polymyxins. The aim of this study was to determine the frequency and risk factors of colistin-related nephrotoxicity in the adult intensive care unit (ICU).

METHODS: In this study, a retrospective review of patients who were followed up between January 1 and December 31, 2016 and who received colistin treatment in the adult ICU was performed. Retrospective computer records of age, sex, site of infection and microorganism breeding, daily creatinine values, and additional diseases were recorded and examined. Nephrotoxicity was assessed using the Risk, Injury, Failure, Loss, and End-stage kidney disease criteria.

RESULTS: A total of 48 patients were included in the study. Of these, $50 \%$ were male. The mean age of the patients with nephrotoxicity was $59.73 \pm 22.38$ years, and the mean age of those without nephrotoxicity was $58.00 \pm 22.39$ years. A. baumanni was observed to be the causative microorganism in all patients, and the most frequent infection was pneumonia. Nephrotoxicity was investigated in $54.2 \%(n=26)$ of the patients. In this study, when risk factors for nephrotoxicity were evaluated, it was found that the presence of nephrotoxicity was greater in cases with chronic obstructive pulmonary disease, malignancy, or abdominal surgery in patients older than 65 years. In addition, mortality was greater in those who developed nephrotoxicity, although it was not statistically significant.
\end{abstract}

CONCLUSION: In this study, the rate of nephrotoxicity was $54.2 \%$ in patients who received colistin in the ICU. Therefore, patients in the adult ICU receiving colistin therapy should be carefully monitored for the development of nephrotoxicity as a side effect.

Keywords: Colistin; end-stage kidney disease criteria; failure; injury; loss; multi-drug resistant pathogens; nephrotoxicity; risk.

Cite this article as: Inci A., Korkmaz Toker M., Bicer I. G., Derbent A., Salihoglu Z. Determination of colistin-related nephrotoxicity and risk factors in intensive care unit. North Clin Istanb 2018;5(2):120-124.

Tntensive care units (ICUs) are the units in which invasive procedures are performed, mechanical ventilation (MV) is applied, and patients who receive intensive drug therapy are followed up; in these units, the hospital-ac- quired infections (HAIs) and mortality rates are also high [1].

Approximately $25 \%$ of HAIs occur in ICU. The frequency of hospital infection and antibiotic susceptibil-

Received: July 15, 2017 Accepted: October 02, 2017 Online: April 11, 2018

Correspondence: Dr. Melike KORKMAZ TOKER. Department of Anesthesiology and Reanimation, University of Health Sciences, Istanbul Kanuni Sultan Suleyman Training and Research Hospital, Istanbul, Turkey.

Phone: +905054747098 e-mail: meltoker@gmail.com

(c) Copyright 2018 by Istanbul Provincial Directorate of Health - Available online at www.northclinist.com 
TABLE 1. RIFLE classification (serum creatinine and GFR criteria)

\begin{tabular}{ll} 
Category & Criteria \\
\hline Risk (R) & Increased creatinine level $x 1.5$ or GFR decrease $>25 \%$ \\
Injury (I) & Increased creatinine level $x 2$ or GFR decrease $>50 \%$ \\
Failure (F) & Increased creatinine level $x 3$, GFR decrease $>74 \%$ or creatinine level $>4 \mathrm{mg} / \mathrm{dl}$ \\
Loss (L) & Persistent acute renal failure or complete loss of function for $>4$ weeks \\
ESKD (E) & ESKD for $>3$ months
\end{tabular}

ESKD: End stage kidney disease.

GFR: Glomerular filtration rate.

ity may vary from country to country, from hospital to hospital, and within different units of the same hospital. Reduction in resistance of patients followed up in ICU, long-term hospitalization, $\mathrm{MV}$, and invasive procedures such as catheterization lead to an increase in the incidence of infections in these units. Multiple antimicrobial resistances occur with the widespread use of broad-spectrum antibiotics in these units [2-4].

Colistin is a cationic polypeptide antibiotic that was introduced in the 1960s. Its use had been banned due to its potential side effects, particularly owing to the nephrotoxicity rates approaching 50\% and subsequent use of other antimicrobials. Recently, its administration has been reinitiated in the treatment of multi-drug resistant pathogens (MDRP) such as Acinetobacter baumannii, Pseudomonas aeruginosa, and carbapenem-resistant Enterobacteriaceae. Nephrotoxicity and neurotoxicity are the main problems encountered in the clinical use of polymyxins [5-8]. In this study, our aim was to determine the frequency and risk factors of colistin-related nephrotoxicity in the adult ICU.

\section{MATERIALS AND METHODS}

This was a retrospective cohort analysis to assess nephrotoxicity in critically ill patients receiving colistin at a university-affiliated tertiary research and training hospital. In this study, patients who received intravenous colistin during follow-up in the adult ICU of University of Health Sciences Istanbul Kanuni Sultan Suleyman Research and Training Hospital between January 01 and December 31, 2016 were retrospectively evaluated. Computer records of age, sex, site of infection and microorganism breeding, daily creatinine values, comorbidities such as diabetes mellitus (DM), cerebrovascular disease (CVD), chronic obstructive pulmonary disease (COPD), malig- nancy, trauma, and presence of abdominal surgery were recorded and examined.

Concurrent use of nephrotoxic antibiotics such as aminoglycoside, vancomycin, and carbapenem has been identified in patients who have received colistin. Patients were excluded if they received colistin therapy for less than 72 hours, had a diagnosis of chronic renal failure according to documented medical history, or were younger than 18 years of age. If a patient received recurrent colistin treatment, only the first treatment was evaluated.

The primary outcome was the occurrence of nephrotoxicity according to the Risk, Injury, Failure, Loss, and End-stage kidney disease (RIFLE) criteria. The RIFLE criteria (Table 1) represent a valuable validated tool for evaluation of acute kidney injury (AKI) based on both change in glomerular filtration rate (GFR) and serum creatinine concentration [9]. These criteria have been validated and continue to be used in literature describing colistin-associated nephrotoxicity [10].

For statistical analysis, SPSS 15.0 package program, chi-square test, and T-test were used. In the analysis results, a $\mathrm{p}$ value less than 0.05 were considered to indicate a statistically significant difference.

\section{RESULTS}

A total of 48 patients met the inclusion criteria and were included in the study. Of these, $50 \%$ were male. A. baumanni was observed to be the causative microorganism in all patients and the most frequent infection was pneumonia. Patients were treated for pneumonia (73\%), blood stream infection (23\%), soft tissue infection (2\%), and urinary system infection (2\%) (Table 2). Nephrotoxicity was investigated in $54.2 \%(n=26)$ of the patients. Overall, the 26 patients with nephrotoxicity were classi- 
TABLE 2. Distribution of infections in patients

\begin{tabular}{lcc} 
& N & $\%$ \\
\hline Pneumonia & 35 & 73 \\
Blood stream infection & 11 & 23 \\
Soft tissue infection & 1 & 2 \\
Urinary system infection & 1 & 2
\end{tabular}

TABLE 3. Distribution of patients according to RIFLE criteria

\begin{tabular}{lcc} 
Criteria (Patient) & $\mathrm{N}$ & $(\%)$ \\
\hline No risk & 22 & $(45.8)$ \\
Risk (R) & 7 & $(14.5)$ \\
Injury (I) & 10 & $(20.8)$ \\
Failure (F) & 9 & $(18.7)$
\end{tabular}

fied as risk ( 7 patients), injury (10 patients), and failure (9 patients) (Table 3 ).

The mean age of the patients with nephrotoxicity was $59.73 \pm 22.38$ years and of those without nephrotoxicity was $58.00 \pm 22.39$ years.
Demographic features of the patients and clinical characteristics are listed in Table 4. The incidence of nephrotoxicity was not affected by other variables.

\section{DISCUSSION}

Hospital infections are one of the major causes of mortality and morbidity in hospitalized patients and cause serious problems particularly in patients in ICU. Inflammatory infections caused by resistant microorganisms are frequent in ICU due to invasive interventions, prolonged hospitalization, and frequent use of broad-spectrum antibiotics [11].

This retrospective cohort study was designed to evaluate the incidence of severe AKI and the associated risk factors in ICU patients, without pre-existing renal impairment, receiving colistin treatment for the MDRP infections.

Colistin is a cyclic structured polypeptide. Nowadays, the increase of multi-drug resistant gram-negative pathogens has attracted interest with respect to colistin. The most important disadvantage of this drug is its nephrotoxic effect, which is the only option in patients with $\mathrm{P}$. aeruginosa and $\mathrm{A}$. baumannii infections, particularly in their last few years. A. baumannii has been iden-

TABLE 4. Demographic and clinical characteristics of patients who received colistin

\begin{tabular}{lccc} 
& $\begin{array}{c}\text { Patients with } \\
\text { nephrotoxicity } \\
(\mathrm{n}=26)\end{array}$ & $\begin{array}{c}\text { Patients without } \\
\text { nephrotoxicity } \\
(\mathrm{n}=22)\end{array}$ & $\mathrm{P}$ \\
\hline Age (years) (mean $\pm \mathrm{SD})$ & $59.73 \pm 22.38$ & $58.00 \pm 22.39$ & 0.39 \\
Gender (M/F) & $15 / 11(58 / 42)$ & $9 / 13(41 / 59)$ & 0.24 \\
$>65$ years, N. (\%) & $13(50)$ & $9(41)$ & 0.52 \\
Diabetes Mellitus, N. (\%) & $9(35)$ & $9(41)$ & 0.65 \\
COPD, N. (\%) & $11(42)$ & $4(18)$ & 0.72 \\
Malignancy, N. (\%) & $3(12)$ & $1(4)$ & 0.38 \\
Cerebrovascular disease, N.(\%) & $5(19)$ & $2(9)$ & 0.32 \\
Postoperative visceral surgery, N. (\%) & $12(46)$ & $7(32)$ & 0.31 \\
Creatinin level before therapy (mg/ dL) (mean $\pm S D)$ & $0.66 \pm 0.24$ & $0.70 \pm 0.18$ & 0.51 \\
Concomitant aminoglycoside use & $1(4)$ & $3(14)$ & 0.22 \\
Concomitant vancomycin use & $12(46)$ & $10(45)$ & 0.56 \\
Concomitant carbapenem use & $26(100)$ & $20(91)$ & 0.11 \\
Concomitant tigecycline use & $0(0)$ & $3(14)$ & 0.52 \\
Duration of treatment (day) (mean $\pm S D)$ & $13.38 \pm 7.17$ & $15.18 \pm 7.12$ & 0.39 \\
Mortality, N. (\%) & $19(73)$ & $14(64)$ & 0.48 \\
\hline
\end{tabular}

COPD: Chronic Obstructive Pulmonary Disease. 
tified as the most frequent cause of hospital infections in elderly patients followed up in ICU [12-14]. Nephrotoxicity and neurotoxicity are the main problems encountered in the clinical use of polymyxins. Nephrotoxicity ratios differ in studies conducted on the subject, and it is thought that this difference may be due to different patient populations and the use of different criteria. In recent years, for obtaining more standardized data, varying criteria have been used, and the RIFLE criteria provide a useful framework for nephrotoxicity $[8,14]$. Ricci et al $[15]$ defined the RIFLE classification as a simple, readily available clinical tool to classify AKI in different populations. Authors concluded their review by stating that the RIFLE classification seems to be a good outcome predictor.

Due to the high sensitivity of the RIFLE criteria with respect to determining acute renal failure, in our study, we decided to use RIFLE as a degree of measuring nephrotoxicity.

In our study, the rate of nephrotoxicity was detected to be $54.2 \%$ in patients who received colistin in ICU. The rate of nephrotoxicity varies widely throughout the published literature. A total of 11 relevant study results [520] have been identified in Table 5 .

The incidence of AKI related to colistin varies widely, ranging from $16.2 \%$ to $77.5 \%$ in the literature [5-20]. This wide variety is likely due to differences in study populations. Bilgili et al. reported a rather high overall AKI incidence, and they explained this high occurrence by the severity of illness. Their median Apache score was 21. The lack of Apache scores of our patients in this study is insufficient to compare our outcome with this study.

In the current study, among the 26 patients with nephrotoxicity, $14.6 \%$ were classified as risk, $20.8 \%$ as injury, and $18.7 \%$ as failure. Pogue et al. presented similar rates of nephrotoxicity in a cohort of 126 patients: $13 \%$ as risk, $17 \%$ as injury, and $17 \%$ as failure.

A. baumanni was observed to be the causative microorganism in all patients, and the most frequent infection was pneumonia. Similar to our study, it was determined that A. baumannii is the most common agent in other studies $[8,18,22]$, and the most frequent infection is pneumonia $[8,12,18,19]$.

When risk factors for nephrotoxicity were evaluated, it was found that nephrotoxicity was higher in the presence of COPD, malignancy, and abdominal surgery in those older than 65 years, and mortality was higher in those who developed nephrotoxicity, although the toxicity was not statistically significant.
Pogue et al. [5] reported that higher colistin doses led to a relatively high rate of nephrotoxicity. Tuon et al. [7] concluded their study stating that vancomycin co-administration likely increases the risk of AKI.

In our country, Köksal et al. [8] showed that older age, presence of COPD, and DM increased the risk of nephrotoxicity. There are several studies that revealed the association between COPD and renal failure. Gadam et al. [23] reviewed prospective and retrospective observational studies that reported the prevalence of chronic kidney disease (CKD) in patients with COPD. They found that patients with COPD have increased odds of developing CKD. The mechanism by which COPD potentiates the development of CKD remains unclear. COPD has been associated with systemic inflammation. This inflammation is also potentially related to development of kidney disease. Mapel et al. [24] examined renal disease in a population-based cohort of persons with COPD. They found that COPD patients have a substantially increased prevalence of renal diseases as well as abnormal renal and hepatic laboratory values. Our results revealed that COPD patients have more nephrotoxicity as studies mentioned above. This result can be explained by stating that COPD patients are also more likely to be prescribed medications with potentially toxic renal side effects.

Other studies on the subject have reported that the presence of malignancy, hypotension, simultaneous vancomycin use, high dose, advanced age, and septic shock are factors that increase nephrotoxicity $[13,14,17,18$, 20-22].

In conclusion, nephrotoxicity seems to be an important adverse effect in our study because of the fact that the risk factors affecting nephrotoxicity were not statistically determined but the rate of development of nephrotoxicity was $54.2 \%$ in patients using colistin. Therefore, periodic assessment of serum creatinine levels, modification of the colistin dose according to renal function, avoidance of coadministration of other nephrotoxic agents (if possible), and shortening the duration of antimicrobial treatment will minimize the potential for nephrotoxic effects of this valuable old antibiotic.

Conflict of Interest: No conflict of interest was declared by the authors.

Financial Disclosure: The authors declared that this study has received no financial support.

Authorship contributions: Concept - A.İ., M.K.T.; Design - A.İ., M.K.T.; Supervision - A.I..; Materials - A.İ., İ.G.B.; Data collection \&/or processing - A.I.', İ.G.B.; Analysis and/or interpretation - A.İ., M.K.T.; Critical review - A.D., Z.S. 


\section{REFERENCES}

1. Palabıyık O, Öğütlü A, Toptaş Y. Ventilator-associated pneumonia and causative microorganisms in intensive care unit: a 2-year retrospective analysis. J Turk Soc Intens Care 2016;14:80-5. [CrossRef]

2. Biberoğlu K. Intensive Care Unit Infections - Risk Factors, Epidemiology and Prevention. Flora 1997;2:79-84.

3. Inan D, Saba R, Keskin S, Öğünç D, Çiftçi C, Günseren F, Mamikoğlu L, Gültekin M. Nosocomial Infections in Akdeniz University Intensive Care Units. Yoğun Bakım Dergisi 2002;2(2):129-135.

4. Camkıran A, Kundakçı A, Araz C, Pirat A, Zeyneloğlu P, Arslan H, et al. Predictors of Multidrug Resistant Acinetobacter Baumannii Infections in Surgical Intensive Care Patients: A Retrospective Analysis. Journal of the Turkish Society of Intensive Care 2011;9: 53-8

5. Pogue JM, Lee J, Marchaim D, Yee V, Zhao JJ, et al. Incidence of and risk factors for colistin-associated nephrotoxicity in a large academic health system. Clin Infect Dis 2011;53:879-84. [CrossRef]

6. Justo JA, Bosso JA. Adverse reactions associated with systemic polymyxin therapy. Pharmacotherapy 2015;35:28-33. [CrossRef]

7. Tuon FF, Rigatto MH, Lopes CK, Kamei LK, Rocha JL, Zavascki AP. Risk factors for acute kidney injury in patients treated with polymyxin B or colistin methanesulfonate sodium. Int J Antimicrob Agents 2014;43:349-52. [CrossRef]

8. Koksal I, Kaya S, Gencalioglu E, Yilmaz G. Evaluation of Risk Factors for Intravenous Colistin Use-related Nephrotoxicity. Oman Med J 2016;31:318-21 [CrossRef]

9. Spapen H, Jacobs R, Van Gorp V, Troubleyn J, Honoré PM. Renal and neurological side effects of colistin in critically ill patients. Ann Intensive Care 2011;1:14. [CrossRef]

10. Gaynes R, Edwards JR; National Nosocomial Infections Surveillance System. Overview of nosocomial infections caused by gram-negative bacilli. Clin Infect Dis 2005;41:848-54. [CrossRef]

11. Yilmaz N, Kose S, AguS N, Ece G, Akkoclu G, Kirakli C. Microorganisms Isolated from Blood Cultures of Intensive Care Unit Patients, their Antimicrobial Susceptibility and Etiological Agents in Nosocomial Bacteremia. ANKEM J 2010;24:12-9.

12. Arslan Zİ, Özbudak E, Türkyılmaz N, Cesur S, Alparslan V, Mirhanoğulları AF, et al. Evaluation of the Use of Colistin on Nephrotoxicity and Mortality in the Intensive Care Unit, Turkiye Klinikleri J Anest Reanim 2015;13:21-4. [CrossRef]
13. Kaya M, Tunçel YI, Kuru RN, Menteș S, Ünver S, Çeken S, et al. Retrospective Evaluation of Colistin Associated Nephrotoxicity at Oncology Hospital Intensive Care Unit, J Turk Soc Intens Care 2014;12: 51-6

14. Inci A, Karabay A, Erus S, Demiraran Y. Nosocomial Infections and Associated Risk Factors in Geriatric Patients in the Intensive Care Unit. Eurasian J Emerg Med 2016; 15: 177-80. [CrossRef]

15. Ricci Z, Cruz D, Ronco C. The RIFLE criteria and mortality in acute kidney injury: A systematic review. Kidney Int 2008;73:538-46.

16. Bahlis LF, Diogo LP, Lemons D, Klaus D. Risk factors for acute kidney injury in patients treated with polymyxin B at a Tertiary Care Medical Center. J Bras Nefrol 2015;37:446-50. [CrossRef]

17. Akajagbor DS, Wilson SL, Shere-Wolfe KD, Dakum P, Charurat ME, Gilliam BL. Higher incidence of acute kidney injury with intravenous colistimethate sodium compared with polymyxin B in critically ill patients at a tertiary care medical center. Clin Infect Dis 2013;57:1300-3.

18. Dewan A, Shoukat M. Evaluation of risk of nephrotoxicity with high dose, extended-interval colistin administration. Indian J Crit Care Med 2014;18:427-30. [CrossRef]

19. Hür E, Çetintürk A, Eminoğlu V, Sungur M, Tavşan Ö, Pişkinpaşa SV, et al. Colistin and Acute Renal Failure: A Centre's Experience. Turk Neph Dial Transpl 2014; 23: 196-201. [CrossRef]

20. Demirtürk N, Demir S, Așçı Z, Doğan N. Evaluation of renal functions in patients treated with colistin. Nobel Med 2016; 12: 74-8

21. Rocco M, Montini L, Alessandri E, Venditti M, Laderchi A, De Pascale G, et al. Risk factors for acute kidney injury in critically ill patients receiving high intravenous doses of colistin methanesulfonate and/or other nephrotoxic antibiotics: a retrospective cohort study. Crit Care 2013;17:R174. [CrossRef]

22. Bilgili B, Haliloğlu M, Gül F, Cinel I. Septic shock is an independent risk factor for colistin-induced severe acute kidney injury: a retrospective cohort study. Int J Clin Exp Med 2016;9:14649-55.

23. Gaddam S, Gunukula SK, Lohr JW, Arora P. Prevalence of chronic kidney disease in patients with chronic obstructive pulmonary disease: a systematic review and meta-analysis. BMC Pulm Med 2016;16:158.

24. Mapel DW, Marton JP. Prevalence of renal and hepatobiliary disease, laboratory abnormalities, and potentially toxic medication exposures among persons with COPD. Int J Chron Obstruct Pulmon Dis 2013;8:127-34. [CrossRef] 